\title{
A framework for comparing customer satisfaction across individuals and product categories *
}

\author{
Michael D. Johnson and Claes Fornell \\ The University of Michigan, Ann Arbor, USA
}

Received March 2, 1990; accepted January 3, 1991

\begin{abstract}
A framework is presented which integrates economic and psychological perspectives in order to compare customer satisfaction across individuals and product categories. The framework lays the foundation for the development of a national index for customer satisfaction that is now in place in Sweden. An important property of any such index is that it allows for comparisons across customers, firms, and industries. A number of propositions are forwarded regarding potentially systematic differences in satisfaction across people and products.
\end{abstract}

\section{Introduction}

As industries and firms worldwide face increasing competition, slower growth rates, and price pressures, greater attention is being placed on customer satisfaction. Satisfaction is an important determinant of customer retention which, in turn, has a very strong effect on profitability (Reichheld and Sasser 1990). It thus plays a very prominent role in marketing strategy and public policy formation (Fornell and Wernerfelt 1987, 1988; Simon 1974). However, our ability to measure and use customer satisfaction on a broad basis depends critically on two questions. First, can customer satisfaction be compared across individ-

\footnotetext{
* The authors thank the Customer Satisfaction Barometer Group at the University of Michigan and Professor Karl-Erik Wärneryd for their valuable comments on an earlier version of the paper. The financial support of the Swedish Post Office is also gratefully acknowledged.

Requests for reprints should be sent to M.D. Johnson at the University of Michigan, School of Business Administration, Ann Arbor, MI 48109-1234, USA.
} 
uals? Second, can customer satisfaction be compared across product categories and industries?

There is a long standing debate in economics regarding the appropriateness of interpersonal comparisons of satisfaction. The debate led many economists to attempt to eradicate satisfaction, as a measurable and comparable entity, from theory development (Johnson 1913; Slutsky 1915; Allen and Hicks 1934; Hicks 1939). Alternatively, a number of theorists have come to view satisfaction as measurable, comparable across individuals, and thus valuable for policy making and strategy formation (Scitovsky 1951, 1976; Little 1957; Simon 1974; Sen 1979). For example, economists have recently shown that an interpersonal comparison of individual welfare functions is possible by first defining a cardinal measure of individual welfare (see Jorgenson 1990).

Less emphasized has been the question of comparing satisfaction across product categories. This is due in large part to the presumption that satisfaction, as a synonym for utility (Simon 1974), makes all products and services comparable, even guns and butter. Yet one can not compare measures of satisfaction from vastly different product categories without first considering the basic differences among the categories themselves.

Any systematic approach to measuring and comparing satisfaction must address both of these questions. As we shall see, the answers involve psychological as well as economic considerations (Wärneryd 1988). Yet economic and psychological discussions of satisfaction have remained quite separate (for notable exceptions see Boring 1950). 1 Economists have been primarily concerned with the theoretical necessity of measuring satisfaction while ignoring the psychological basis of satisfaction judgments (Scitovsky 1976). In contrast, psychologists have been more concerned with the processes and antecedents of perceived satisfaction (Yi 1990) while ignoring the comparability of satisfaction across people and products.

We will attempt to integrate psychological and economic perspectives in order to develop a framework for making both interpersonal

\footnotetext{
1 This has not always been the case. During the eighteenth and nineteenth centuries the development of hedonism and utilitarianism in economics was closely linked to the development of associationism and resulting learning theories in psychology. Satisfaction, defined as the increasing of pleasure or the decreasing of pain, was felt to reinforce the actions leading to it.
} 
and product category comparisons of satisfaction. Our aim is to reconcile the debate among economists and psychologists regarding the comparability of satisfaction across people and products. Although we acknowledge that satisfaction may not be directly measurable, we will argue that it is indirectly or proximally measurable via a multiple indicators approach. Satisfaction is therefore comparable as a theoretical or latent construct (Simon 1974).

Our framework incorporates two general factors that indirectly affect satisfaction judgments, individual differences and product category differences. These differences can be captured indirectly via expectations and performance perceptions which greatly simplifies the researcher's task. Finally, our discussion offers some general propositions regarding potentially systematic differences in customer satisfaction across individuals and product categories. We begin by briefly reviewing the theoretical arguments for and against making interpersonal and interproduct comparisons of satisfaction.

\section{Interpersonal comparisons of satisfaction}

Is it proper to compare the satisfaction levels of two different individuals? The debate over the appropriateness of interpersonal comparisons of satisfaction appears to have come full circle. Early on Bentham (1802) defended the comparability and additivity of satisfaction from a practical standpoint. He reasoned that denying interpersonal comparisons of satisfaction runs counter to all political reasoning. At the same time, Bentham acknowledged the significant problems inherent in satisfaction measurement and in comparing satisfaction across people. Such comparisons generally require value judgments on the part of the researcher or policy maker (De Graaff 1957). Although interpersonal comparisons of satisfaction were considered both possible and necessary, they were not without error.

Given its lack of 'purity', subsequent economic approaches sought to eradicate satisfaction measurement and comparison based on the belief that it was not necessary for theory development. Economists including Johnson (1913), Slutsky (1915), and Hicks (Allen and Hicks 1934; Hicks 1939) sought to insulate demand theory from psychological and philosophical assumptions. Robbins went so far as to claim that satisfaction comparisons have 'no place in pure science' (Meeks 1984: 
58). The most obvious and unfortunate danger of such eradication is that it takes as a given, and hence ignores, the customer (Scitovsky 1976).

Satisfaction has more recently re-emerged as a measurable and comparable theoretical entity. Reminiscent of Bentham, Scitovsky (1951) argues that virtually all policy recommendations require interpersonal comparisons of welfare. In a similar vein, Little (1957) suggests that comparisons of satisfaction are made all the time which is proof enough that they are possible. The important question is not whether interpersonal comparisons of welfare can be made, but how (Sen 1979).

One approach to the measurement problem is to treat satisfaction as a synonym for utility (Simon 1974). Measuring satisfaction then becomes equivalent to measuring utility. Perhaps the most systematic approach taken to utility assessment or measurement in recent years is that based on von Neumann and Morgenstern's (1947) axioms of rationality (Schoemaker 1982; von Winterfeldt and Edwards 1986). This approach presumes that as long as peoples' preferences are consistent with the axioms, a usable utility function may be constructed at either the individual or group level. Though the rationality axioms have come under attack and are systematically violated (Kahneman and Tversky 1979; Einhorn and Hogarth 1981), the approach remains a valuable basis for decision analysis and policy formation (von Winterfeldt and Edwards 1986). However, such decision analytic techniques are rather involved and time consuming, making them infeasible in many research settings.

Simon (1974) suggests a qualitatively different philosophical approach to measuring and studying satisfaction which is both widely applicable and reconciles the divergent economic views. He argues that it is scientifically wrong, in principle, to presume that satisfaction can not be measured and compared across individuals. Any theoretical construct can be operationalized 'by choosing a measurable proxy for it' (Simon 1974: 66). Essentially Simon views satisfaction as a latent or abstract theoretical construct. As earlier economists have argued, it can not be equated with or measured directly by any one observable variable. At the same time, it can be measured indirectly through the use of proxies or indicators.

Building on Simon's argument, a more systematic approach is to adopt the framework of theoretical empiricism (Wold 1982, 1989) as a 
basis for satisfaction research. As originally intended, satisfaction should be viewed as a latent or theoretical construct. As a latent construct, satisfaction is empirically measurable as a weighted average of satisfaction indicators. ${ }^{2}$ Even though the original indicators may not be continuous, the latent variable scores or scale values that result provide an index or continuous measure of satisfaction.

It is then possible to address the issue of measurement error through the quality and number of proxies or indicators used to tap the satisfaction construct. Any single indicator of satisfaction, such as self-rated satisfaction, contains both information regarding latent satisfaction as well as measurement error. If several measures can be found that operationalize the construct, the greater the chances for an explicit modeling of errors in observation and using the covariance of the measures to provide a stable latent construct (Fornell 1989).

\section{Interproduct comparisons of satisfaction}

In addition to the question of interpersonal comparisons of satisfaction, a second and equally important question concerns comparisons of satisfaction across product categories. Is satisfaction in one product category comparable to satisfaction in a very different category? For example, can different industries such as television programing and airline service be compared with respect to how well they satisfy their customers?

The straightforward answer is that theoretical terms such as satisfaction were introduced in order to make such comparisons. Satisfaction, similar to utility (Simon 1974), is by its very nature a common denominator on which all consumption experiences may be compared. However, it would not be useful to presume that satisfaction with, say, a compact disk player and a washing machine can be compared without considering the inherent differences in the categories as well as the individuals involved. The bases of satisfaction judgments may be very different in the two cases.

Only recently have we begun to understand just how customers actually go about comparing products across categories. One particu-

2 This is similar to the economist's notion of constructing a social welfarc function as an averagc of individual welfare functions. 
larly relevant finding is that nonprice comparisons typically occur at a level of abstraction where products are comparable or described by the same attributes (Johnson 1984, 1988). The more noncomparable or dissimilar the alternatives, the more abstract the attributes used to compare the products. Similar products, such as brands from the same product category, are typically compared on relatively concrete attributes, whether it be televisions on screen size or automobiles on gas mileage. A motorcycle and an automobile, being moderately noncomparable or dissimilar, are often compared at a more intermediate level of abstraction on attributes such as safety and convenience. More noncomparable or dissimilar alternatives, such as an automobile and a washing machine, are often compared at an even more abstract level on attributes such as practicality and fun.

This suggests that people do not typically compare products across categories on the basis of overall satisfaction. In fact, fun and practicality, or pleasure and pain to use Bentham's terminology, may be the most abstract attributes on which customers are comfortable making comparisons across categories (Johnson 1984). Theoretically, however, satisfaction is probably the ultimate in abstract attributes because it describes the customer's total consumption experience. Thus it is not only a common denominator for comparing products across categories, it also encompasses post-purchase or 'after the fact' economic utility.

Importantly, Simon's (1974) argument in favor of interpersonal comparisons of satisfaction appears equally valid for interproduct comparisons. It is a scientific cower to simply presume that satisfaction cannot be measured and compared across product categories. Even if customers use attributes that are more concrete than overall satisfaction to compare products, these comparisons may be captured theoretically at the common, more abstract level of overall satisfaction.

It is nevertheless necessary to address systematic differences across product categories when conducting satisfaction research. For example, consider the observation that customers typically do not abstract beyond 'pleasure and pain'. Consistent with this notion, research on risky choice suggests that losses (i.e., pains) and gains (i.e., pleasures) are treated differently. As a rule, a loss looms larger or is perceptually greater than a gain of equal amount (Cohen et al. 1987; Kahneman and Tversky 1979; Puto 1987). Now consider that certain product categories may be primarily associated with reducing discomfort or pain (e.g., aspirin, air conditioning) while others with increasing pleasure 
(e.g., books, movies). As a result, any given difference in objective performance across products or services should, other things equal, result in a wider range of perceived satisfaction in some categories (i.e., pain reducers) than others (i.e., pleasure increasers). Other differences in satisfaction ascribable to product category or industry differences are explored in a later section of the paper.

\section{The antecedents of satisfaction}

Psychological treatments of satisfaction have taken the comparability of satisfaction across people and product categories more or less as a given. Instead, psychologists have focused on delineating the process underlying customer satisfaction and its antecedents. This research suggests that the primary antecedents of satisfaction are a product's perceived performance and the customer's expectations regarding that performance (Churchill and Surprenant 1982; Oliver 1980, 1981; Westbrook and Oliver 1981; Yi 1990). One psychological dimension of satisfaction is whether one's expectations are confirmed or disconfirmed by performance.

Viewing expectations or some other reference point as a baseline for performance evaluation is not unique to psychology. In welfare economics Simon (1974) similarly emphasizes the importance of considering aspiration levels when making satisfaction comparisons. Viewing expectations and/or aspirations as perceptual reference points in a disconfirmation paradigm is psychologically attractive. Generally, human perception is tuned to differences in magnitudes from reference points rather than absolute magnitudes (Helson 1964; Puto 1987).

\section{A framework for comparing customer satisfaction}

We propose a framework for measuring and comparing satisfaction which incorporates the key factors identified in both economic and psychological research. The framework is presented in fig. 1. The primary antecedents of perceived satisfaction are product expectations and perceived product performance. Notice that expectations and performance are viewed as directly affecting satisfaction. Alternatively, Oliver (1980, 1981; see also Oliver and DeSarbo 1988) suggests that 


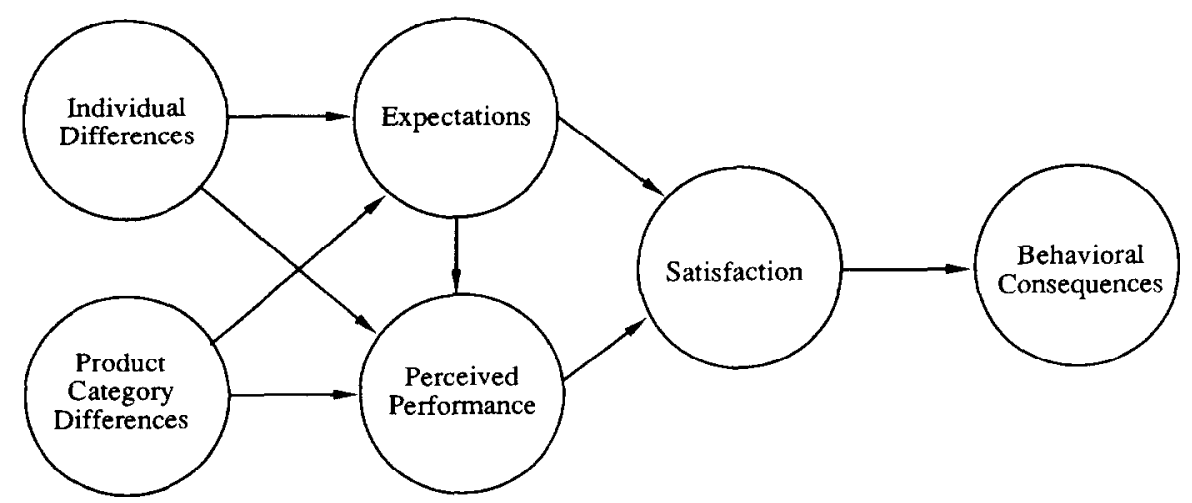

Fig. 1. A framework for satisfaction research.

expectation and product performance effects are mediated via an intermediate disconfirmation construct (see, for example, Churchill and Surprenant 1982).

Our conceptualization is based on several considerations. First, we are more concerned with developing a parsimonious framework that captures the primary psychological antecedents of satisfaction than with specifying the exact psychological process. Second, the proposed framework is consistent with Van Raaij's (1981) general model for economic psychology. This model views behavior (e.g., product performance) and perceptions of economic conditions (e.g., expectations) as the primary antecedents of subjective well-being (i.e., satisfaction). Third, research suggests that there are situations (described below) where either expectations or performance have very direct and primary effects on satisfaction (Churchill and Surprenant 1982; Westbrook and Reilly 1983). Finally we shall argue that, in a dynamic perspective, customers' experience with products and services should result in a general increase in perceived satisfaction. This increase can not be explained strictly on the basis of disconfirmation.

How then do individual and product category differences influence satisfaction? As shown in fig. 1, we view these factors as affecting satisfaction via customers' expectations and/or perceptions of performance. The justification is based on the notion that expectations and performance perceptions are the primary antecedents of satisfaction. They should, therefore, mediate the effects of individual and product category differences on satisfaction judgments. 
Individuals hold particular expectations and focus on particular performance dimensions. For example, the observation that satisfaction increases with age (Pickle and Bruce 1972) is consistent with older customers being more pessimistic (i.e., holding lower expectations) and/or judging products on more positive dimensions. Similarly, different product categories are evaluated with different expectations and performance dimensions in mind. The point is that expectations and performance perceptions indirectly capture any salient individual or product category differences. If expectations and current performance perceptions are assessed, individual and product category differences are implicitly captured.

Expectations, product performance, and experience

A number of theories and studies suggest just when either expectations or perceived performance may be the primary determinant of satisfaction. According to assimilation-contrast theory (Sherif and Hovland 1961) the relative importance of performance versus expectations depends on their discrepancy. Expectations may dominate perceptions of satisfaction when objective performance is within some acceptable range of expectation. Studies suggest that when the disparity between objective performance and expectations is small, perceptions of performance may be assimilated toward one's expectations (Anderson 1973; Olshavsky and Miller 1972). If performance is outside some range then a contrast occurs and perceived performance becomes the driving force (Howard and Sheth 1969).

However, the strength of one's expectations and the salience or ambiguity of available product performance information likely determine just when assimilation or contrast effects occur (Alloy and Tabachnik 1984). When performance expectations are strong and more salient than current performance information, that information is more likely to be used to confirm expectations producing an assimilation effect (Einhorn and Hogarth 1978). When, in contrast, current performance information is very salient and unambiguous, perceptions are less likely to be assimilated toward expectations (Hoch and Ha 1986). A direct relationship from expectations to current performance in fig. 1 captures the potential for assimilation effects in current performance perceptions.

This suggests that a customer's prior experience with products or 
services is a major individual difference dimension affecting satisfaction judgments. Past performance information provides a basis for one's expectations, attitudes, and stored evaluations (Howard 1977, 1989). An individual's product experience and resulting access to past performance information should directly affect the antecedents of satisfaction.

Consider a totally new category of products in which customers have no experience and for which past performance information is not available. Any basis for expectations will be weak and indirect, perhaps based on a related or more general category of products. In such cases, satisfaction is likely judged relative to the provision of more basic needs (Westbrook and Reilly 1983). Current performance should be the primary determinant of satisfaction.

As customer experience with the product grows and past performance information becomes available, more product-specific expectations develop. Initially based on a relatively small amount of past performance information, these early expectations are held with little confidence (Howard 1977, 1989). While the effects of expectations on satisfaction should increase, as via disconfirmation, perceived performance should continue to be the primary determinant of satisfaction.

As experience continues to grow and substantial past performance information accumulates, expectations should increase in both accuracy and confidence. For customers with extensive experience, which may be the norm for many commonly purchased nondurables (e.g., staples), expectations should become strong, stable and generally consistent with a product's perceived performance.

At some point, expectations and performance perceptions may become indistinguishable. Consider the reaction of customers when asked how they expect commonly purchased and consumed products to perform, such as milk or flour. Recent research on price expectations (Blomqvist 1983; Oliver and Winer 1987; Pruitt et al. 1988; Webley and Spears 1986) is consistent with this general scenario. This research suggests, for example, that as the amount of available past price information grows, price expectations become increasingly stable and consistent with actual prices (Johnson and Plott 1989).

The discussion suggests systematic changes in the antecedents of satisfaction with increases in customer experience. These changes are depicted in fig. 2 a through $2 c$. Initially, when there is little to no experience and expectations are uncertain, satisfaction should be prim- 


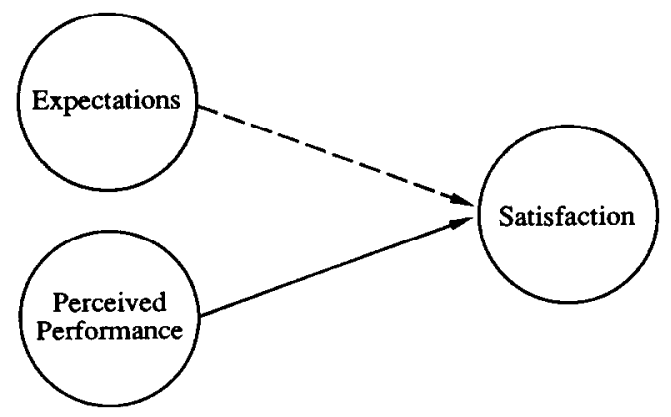

(a) Limited experience.

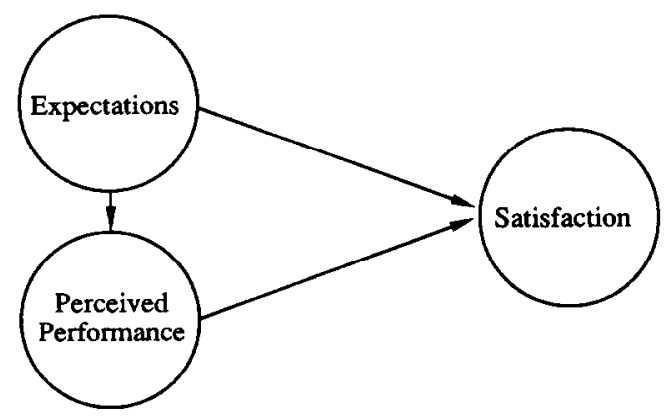

(b) Intermediate experience.

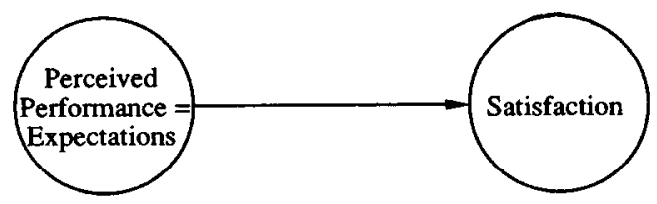

(c) Extreme experience.

Fig. 2. Satisfaction and customer experience.

arily a function of current product performance (see, for example, Churchill and Surprenant 1982). Importantly, the relatively weak expectations should have little or no effect on perceived performance (fig. 2a).

As a customer's product experience grows, expectations should become strong and their effect on satisfaction should increase. As depicted in fig. $2 b$, assimilation effects should also become more preva- 
lent where expectations may directly affect performance perceptions. That is, incoming information may be used more to confirm than disconfirm expectations (Alloy and Tabachnik 1984; Einhorn and Hogarth 1978). Finally, at more extreme levels of experience or for certain product categories (e.g., commonly purchased nondurables), current performance and expectations may coincide and become indistinguishable as theoretical constructs (fig. 2c). This assumes, however, that there are no significant changes or 'shocks' in the customers' product environment.

Notice that the models in fig. 2 are special cases of the general framework presented in fig. 1. As customer experience grows, the importance of the relationships linking expectations to satisfaction and current performance should grow. Eventually, current performance and expectations may coincide. This suggests that product expectations, as a separate theoretical construct, does not play a fundamental role in satisfaction judgments at the extremes of experience.

\section{Experience and levels of satisfaction}

We also expect a general increase in perceived satisfaction with experience. As suggested above, expectations and product performance may become well integrated and difficult to distinguish as experience grows. Similarly, increases in experience and knowledge should result in strong brand or product concepts (Howard 1977, 1989) or integrated product schemas (Alba and Hutchinson 1987). The evaluative or attitudinal components of these brand concepts or schemas should be generally positive.

The more experience we accumulate regarding any particular product or service the more likely we are to be satisfied with its repeated purchase and consumption. Put differently, repeat purchases and accumulated product experience tend to develop for products with existing positive evaluations (Howard 1977). In a competitive environment, people generally do not continue to purchase products toward which they are ambivalent or hold negative evaluations. The strength of these positive evaluations should also contribute to the relationship through the assimilation of belief inconsistent information. Finally, rese arch on low involvement and 'noncognitive' based preferences suggests a general positive relationship between experience and product evaluations. Positive evaluations may result simply from one's habituation and 
familiarity with a product or object (Zajonc and Markus 1982). Empirically the proposed positive experience-satisfaction relationship is consistent with studies that show satisfaction increasing with age (Pickle and Bruce 1972) and competence (Westbrook and Newman 1978).

An important corollary to this relationship is that satisfaction should increase with the maturity of a product or service category. This prediction is based on the observation that customer experience is generally correlated with a product's maturity or stage in the product life cycle (Howard 1983). Naturally, however, there are situations where satisfaction may not increase with experience or product maturity. This would include choice situations where customers' options are limited or restricted. Experience may result in negative stored evaluations and resulting lower levels of satisfaction in such cases. ${ }^{3}$ This scenario is explored in more detail below.

To summarize, there is an evaluative component of a customer's experience and integrated product knowledge. Consistent with the framework outlined in fig. 1, this individual difference component should affect expectations and, as a result, perceptions of satisfaction. The result should be a general positive relationship between experience and satisfaction.

The aggregation problem:

Fundamentals of a customer satisfaction index

Thus far we have presented arguments in favor of making interpersonal as well as interproduct comparisons of satisfaction. We have also argued that the basis, as well as the general level, of satisfaction should systematically change with individual level experience and product category maturity. In order to develop an index of customer satisfaction and understand its implications we need to consider the aggregation problem more explicitly. Certainly it seems possible to compare an individual's satisfaction with different products as well as to compare the satisfaction of different individuals. But what happens if we group a number of individuals and compute average satisfaction as some sort of index over different product categories? After all, firms and policy makers are typically interested in representative statistics of their customer base, not an individual customer.

${ }^{3}$ The opposite would be true when scarcity itself becomes a desirable characteristic (c.g., fashions, luxury automobiles, nightclubs). 
The possible scenarios described in table 1 illustrate the effects of individual and product differences on average satisfaction. The choice alternatives available within a given category or market may be relatively homogeneous (i.e., an undifferentiated commodity) or more heterogeneous (i.e., differentiated brands). Similarly, the customers who purchase and consume these alternatives may be homogeneous (i.e., similar needs and wants) or heterogeneous (i.e., dissimilar needs and wants). Note that products are unlikely to be very heterogeneous when customers are themselves very homogeneous, at least not in the long run.

Where both customers and products are homogeneous we expect average satisfaction to be high. This situation describes very well the market for staples in relatively mature product categories that show little change over time. This would include commodities and basic food products such as milk, salt, or flour. Recall that customers are likely to have considerable experience and resulting positive brand concepts in these more mature categories (Howard 1977, 1983) resulting in relatively high levels of satisfaction.

Now consider those situations where products remain homogeneous yet very significant individual differences exist. Average satisfaction should be much lower. Consider, for example, natural monopolies or

Table 1

The aggregation problem.

\begin{tabular}{|c|c|c|}
\hline & \multicolumn{2}{|c|}{ Within-category product alternatives } \\
\hline & Homogeneous & Heterogeneous \\
\hline \multicolumn{3}{|l|}{ Customers } \\
\hline Homogeneous & $\begin{array}{l}\text { Satisfaction should } \\
\text { be generally high } \\
\text { and increase with } \\
\text { experience (e.g., } \\
\text { staples). }\end{array}$ & $\begin{array}{l}\text { This situation } \\
\text { should not persist. }\end{array}$ \\
\hline Heterogeneous & $\begin{array}{l}\text { Satisfaction should } \\
\text { remain relatively low } \\
\text { as many customers' } \\
\text { needs and wants are } \\
\text { left unsatisfied } \\
\text { (e.g., monopolies, } \\
\text { public utilities). }\end{array}$ & $\begin{array}{l}\text { Satisfaction should } \\
\text { start relatively low } \\
\text { and increase with } \\
\text { experience, and thus } \\
\text { vary more across } \\
\text { customers and cate- } \\
\text { gories (e.g., diff- } \\
\text { erentiated brands). }\end{array}$ \\
\hline
\end{tabular}


public utilities that produce a very limited array of products or services for mass consumption (e.g., an electric company, a local police department, a state run telephone or television company). The narrow range of available choice alternatives will satisfy some customers while others will be forced to consume a product or service that fails to fit their particular needs.

As experience grows, the satisfied customers should become increasingly satisfied as their stored positive evaluations and expectations grow. At the same time, the dissatisfied customers may become increasingly dissatisfied as their negative evaluations perpetuate. At minimum, significant levels of dissatisfaction are likely to persist due to the customers' lack of choice alternatives. Even with growing customer experience aggregate satisfaction should remain relatively low.

A third possibility exists where a heterogeneous set of product alternatives is available for heterogeneous individuals. This is characteristic of many durable and nondurable product and service categories (e.g., soft drinks, automobiles, restaurants). Unlike homogeneous products vying for homogeneous customers, a matching problem exists here. In less mature or constantly evolving markets (e.g., personal computers) many customers will still be searching for the alternatives that satisfy their particular needs. In more mature or stable markets (e.g., soft drinks) more customers are likely to have found their niche. Therefore, we would expect satisfaction to vary considerably from category to category at any one point in time. Only where it is economically feasible to offer a distinct alternative to each distinct market niche will satisfaction levels approach those for homogeneous products and customers.

Overall, the discussion suggests that average satisfaction should be higher for homogeneous populations than for heterogeneous populations. Satisfaction should also increase with experience when that experience leads to a matching of heterogeneous customers with heterogeneous products that satisfy more individual level needs.

\section{Discussion}

Satisfaction comparisons across people and product categories are possible but not without error. As an abstract or latent construct, satisfaction is a common denominator on which products and people 
may be compared. We have presented a framework for making satisfaction comparisons which is based on this principle and which integrates economic and psychological perspectives. This framework is operationalized in the National Customer Satisfaction Index as applied in Sweden (Fornell 1990). A particular approach for measuring satisfaction is suggested and several propositions are forwarded regarding systematic differences in customer satisfaction across individuals and product categories.

\section{Satisfaction and theoretical empiricism}

It is important that future research adopt an empirical approach that acknowledges both the nature of the satisfaction construct and the measurement problems associated with satisfaction research. The approach suggested here views satisfaction as a latent construct at a level of abstraction where all products and services are comparable. As a latent construct, satisfaction can be measured proximally (though not equated) with observable indicators. Such indicators might include self-rated satisfaction, judged distance to some hypothetical ideal product or service (the matching problem), perceptions of the confirmation or disconfirmation of expectations (the expectations problem), or behaviors that reflect latent satisfaction.

The indicators used will depend largely on the particular application. Satisfaction has a number of behavioral consequences, including customer complaints, product repurchase, and brand switching (Fornell and Wernerfelt 1987, 1988). As in the National Satisfaction Index for Sweden where the focus is on such consequences, confirmation of expectations, distance to some ideal, and self-ratings of satisfaction may be used to tap latent satisfaction. If, in contrast, the research focus is on the antecedents of satisfaction, the behavioral consequences may themselves be used to reflect latent satisfaction.

The framework views individual and product category differences as affecting satisfaction via expectations and perceptions of current performance. Not only is this psychologically attractive, it provides a straightforward answer to the traditional problems associated with interpersonal and interproduct comparisons of satisfaction. Empirically, any individual or product category differences can be controlled for or incorporated indirectly by measuring customers' expectations and perceptions of current performance. This greatly simplifies 
the researcher's task. As long as current performance and expectation measures are available, a meaningful satisfaction construct can be operationalized. Again, the problem is not whether interpersonal and interproduct comparisons of satisfaction are possible, but rather how we do so and whether such comparisons improve our understanding of customer behavior.

\section{Propositions}

Several propositions have been forwarded in the course of our discussion. Summarized in table 2, these propositions suggest systematic differences in both the range and mean levels of satisfaction across different types of customers and product categories.

Proposition P1 states that satisfaction should vary more across customers when products reduce losses than when they increase gains. This proposition is based on the notion that losses loom larger than equivalent gains (Kahneman and Tversky 1979). Proposition P2 states that in a competitive environment, satisfaction should generally increase with customer experience. Recall that, with experience, customers typically develop positive stored evaluations and resulting product expectations (Howard 1977). In addition, experience may be necessary to match a heterogeneous array of products and services with a heterogeneous customer population. Customer experience should generally grow with the maturity of a product category. Proposition P3 thus states that satisfaction should increase with maturity. Finally, proposition P4 states that satisfaction should be low when alternatives

Table 2

General propositions regarding customer satisfaction across individuals and product categories.

P1: Customer satisfaction should vary more across customers for products or services that reduce losses than for products or services that increase gains.

P2: Customer satisfaction should generally increase with the customers' product or service experience.

P3: Customer satisfaction should generally increase with the maturity of a product or service category.

P4: Customer satisfaction should be relatively low when product or service homogeneity is high relative to heterogeneous customer preferences. 
are homogeneous relative to heterogeneous preferences. This is consistent with basic marketing and economic principles.

\section{Future research}

An important next step is to empirically examine these as well as other potentially systematic differences in satisfaction across people and products. An objective of the Swedish customer satisfaction index is to establish a series of baselines for satisfaction across different industries and customer populations. These baselines could then be used in the interpretation of satisfaction measures and in the development of marketing strategy and public policy. Interpersonal and interproduct comparisons of satisfaction are certainly possible and necessary for policy and strategy development. Yet they should not be made irrespective of the individuals and categories involved.

\section{References}

Alba, J.W, and J.W. Hutchinson, 1987. Dimensions of consumer expertise. Journal of Consumer Research 13, 411-454.

Allen, R.G.D. and J.R. Hicks, 1934. A reconsideration of the theory of value. Economica 1, $196-219$.

Alloy, L.B. and N. Tabachnik, 1984. Assessment of covariation by humans and animals: The joint influence of prior expectations and current situational information. Psychological Review 91 , 112-149.

Anderson, R.E., 1973. Consumer dissatisfaction: The effects of disconfirmed expectancy on perceived product performance. Journal of Marketing Research 10, 38-44.

Bentham, J., 1802. In: E. Dumont, Theory and legislation. London: Trubner, 1871.

Blomqvist, H.C., 1983. On the formation of inflationary expectations: Some empirical evidence from Finland, 1979-1980. Journal of Economic Psychology 4, 319-334.

Boring, E.G., 1950. A history of experimental psychology. (2nd ed.). New York: Appleton-Century-Crofts.

Churchill, G.A. and C. Surprenant, 1982. An investigation into the determinants of customer satisfaction. Journal of Marketing Research 19, 491-504.

Cohen, M., Y. Jaffray and T. Said, 1987. Experimental comparison of individual behavior under risk and under uncertainty for gains and losses. Organizational Behavior and Human Decision Processes 39, 1-22.

De Graaff, J.V., 1957. Theoretical welfare economics. Cambridge: Cambridge University Press.

Einhorn, H.J. and R.M. Hogarth, 1978. Confidence in judgment: Persistence of the illusion of validity. Psychological Review 85, 395-416.

Einhorn, H.J. and R.M. Hogarth, 1981. Behavioral decision theory: Processes of judgment and choice Annual Review of Psycholngy 32, 53-88

Fornell, C., 1989. The blending of theoretical and empirical knowledge in structural equations 
with unobservables. In: H. Wold (ed.), Theoretical empiricism. New York: Paragon House. pp. 153-173.

Fornell, C., 1990. The National Customer Satisfaction Barometer. Working paper, the University of Michigan, School of Business, Ann Arbor, MI.

Fornell, C. and B. Wernerfelt, 1987. Defensive marketing strategy by customer complaint management: A theoretical analysis. Journal of Marketing Research 24, 337-346.

Fornell, C. and B. Wernerfelt, 1988. A model for customer complaint management. Marketing Science 7, 287-298.

Helson, H., 1964. Adaptation-level theory. New York: Harper \& Row.

Hicks, J.R., 1939. Value and capital: An enquiry into some fundamental principles of economic theory. Oxford: Oxford University press.

Hoch, S.J. and Y. Ha, 1986. Consumer learning: Advertising and the ambiguity of product experience. Journal of Consumer Research 13, 221-233.

Howard, J.A., 1977. Consumer behavior: Application of theory. New York: McGraw-Hill.

Howard, J.A., 1983. Marketing theory of the firm. Journal of Marketing 47, 90-100.

Howard, J.A., 1989. Consumer behavior in marketing strategy. Englewood Cliffs, NJ: Prentice Hall.

Howard, J.A. and J. Sheth, 1969. The theory of buyer behavior. New York: Wiley.

Johnson, W.E., 1913. The pure theory of utility curves. Economic Journal 23, 483-513.

Johnson, M.D., 1984. Consumer choice strategies for comparing noncomparable alternatives. Journal of Consumer Research 11, 741-753.

Johnson, M.D., 1988. Comparability and hierarchical processing in multialternative choice. Journal of Consumer Research 15, 303-314.

Johnson, M.D. and C.R. Plott, 1989. The effect of two trading institutions on price expectations and the stability of supply-response lag markets. Journal of Economic Psychology 10, 189-216.

Jorgenson, D.W., 1990. Aggregate consumer behavior and the measurement of social welfare. Econometrica 58, 1007-1040.

Kahneman, D. and A. Tversky, 1979. Prospect theory: An analysis of decision under risk. Econometrica 47, 263-291.

I.ittle, I.M.D., 1957. A critique of welfare economics, 2nd edition. Oxford: Oxford University Press.

Meeks, J.G.T., 1984. 'Utility in economics: A survey of the literature'. In: C.F. Turner and E. Martin (eds.), Surveying subjective phenomena, Vol. 2. New York: Russell Sage Foundation. pp. 41-91.

von Neumann, J. and O. Morgenstern, 1947. Theory of games and economic behavior (2nd ed.). Princeton, NJ: Princeton University Press.

Oliver, R.L., 1980. A cognitive model of the antecedents and consequences of satisfaction decisions. Journal of Marketing Research 17, 460-469.

Oliver, R.L., 1981. Measurement and evaluation of satisfaction processes in retail settings. Journal of Retailing 57, 25-48.

Oliver, R.L. and W.S. DeSarbo, 1988. Response determinants in satisfaction judgments. Journal of Consumer Research 14, 495-507.

Oliver, R.L. and R.S. Winer, 1987. A framework for the formation and structure of consumer expectations: Review and propositions. Journal of Economic Psychology 8, 469-499.

Olshavsky, R.W. and J.A. Miller, 1972. Consumer expectations, product performance, and perceived product quality. Journal of Marketing Research 9, 19-21.

Pickle, H.B. and R. Bruce, 1972. Consumerism, product satisfaction/dissatisfaction: An empirical investigation. Southern Journal of Business 7, 87-100.

Pruitt, S.W., R.J. Reilly and G.E. Hoffer, 1988. The effect of media presentation on the formation of economic expectations: Some initial evidence. Journal of tconomic Psychology 9, 315-325.

Puto, C.P., 1987. The framing of buying decisions. Journal of Consumer Research 14, 301-315. 
Reichtheld, F.F. and W.E. Sasser, Jr., 1990. Zero defections: Quality comes to services. Harvard Business Review, September-October, 105-111.

Schoemaker, P.J.H., 1982. The expected utility model: Its variants, purposes, evidence and limitations. Journal of Economic Literature 20, 529-563.

Scitovsky, T., 1951. The state of welfare economics. American Economic Review 41, 303-315.

Scitovsky, T., 1976. The joyless economy: An inquiry into human satisfaction and consumer dissatisfaction. Oxford: Oxford University Press.

Sen, A., 1979. 'Interpersonal comparisons of welfare'. In: M.J. Boskin (ed.), Economics and human welfare: Essays in honor of Tibor Scitovsky. New York: Academic Press. pp. 183-201.

Sherif, M. and C.I. Hovland, 1961. Social judgment: Assimilation and contrast effects in communication and attitude change. New Haven, CT: Yale University Press.

Simon, J.L., 1974. Interpersonal welfare comparisons can be made - and used for redistribution decisions. Kyklos 27, 63-98.

Slutsky, E.E., 1915. Sulla teoria del bilancio del consumatore. Giornale Degii Economisti 51, 1-26.

Van Raaij, W.F., 1981. Economic psychology. Journal of Economic Psychology 1, 1-24.

Wärneryd, K.-F., 1988. 'Fconomic psychology as a field of Study'. In: W.F. van Raaij, G.M. van Veldhoven and H.E. Wärneryd (eds.), Handbook of economic psychology. Dordrecht: Kluwer: pp. 2-41.

Webley, P. and R. Spears, 1986. Economic preferences and inflationary expectations. Journal of Economic Psychology 7, 359-369.

Westbrook, R.A. and J.W. Newman, 1978. An analysis of shopper dissatisfaction for major household appliances. Journal of Marketing Research 15, 456-466.

Westbrook, R.A. and R.L. Oliver, 1981. 'Developing better measures of consumer satisfaction: Some preliminary results'. In: K.B. Monroe (ed.), Advances in consumer research. Ann Arbor, MI: Association for Consumer Research. pp. 94-99.

Westbrook, R.A. and M.D. Reilly, 1983. "Value-percept disparity: An alternative to the disconfirmation of expectations theory of consumer satisfaction'. In: R.P. Bagozzi and A.M. Tybout (eds.), Advances in consumer research. Ann Arbor, MI: Association for Consumer Research. pp. 256-261

von Winterfeldt, D. and W. Edwards, 1986. Decision analysis and behavioral research. Cambridge: Cambridge University Press.

Wold, H., 1982. 'Systems under indirect observations using PLS'. In: C. Fornell (ed.), A second generation of multivariate analysis: Methods. New York: Praeger, pp. 325-347.

Wold, H., 1989. Theoretical empiricism. New York: Paragon House.

Yi, Y., 1990. 'A critical review of consumer satisfaction'. In: V.A. Zeithaml (ed.), Review of marketing 1990. Chicago, IL: American Marketing Association. pp. 68-123.

Zajonc, R.B. and H. Markus, 1982. Affective and cognitive factors in preferences. Journal of Consumer Research 9, 123-131. 